\title{
Image of the month: Left ventricular aneurysm
}

\author{
Authors: Maliha Iqbal, ${ }^{A}$ Eleanor Denny, ${ }^{B}$ Shobhit $\operatorname{Garg}^{C}$ and Akeel Jubber ${ }^{D}$
}

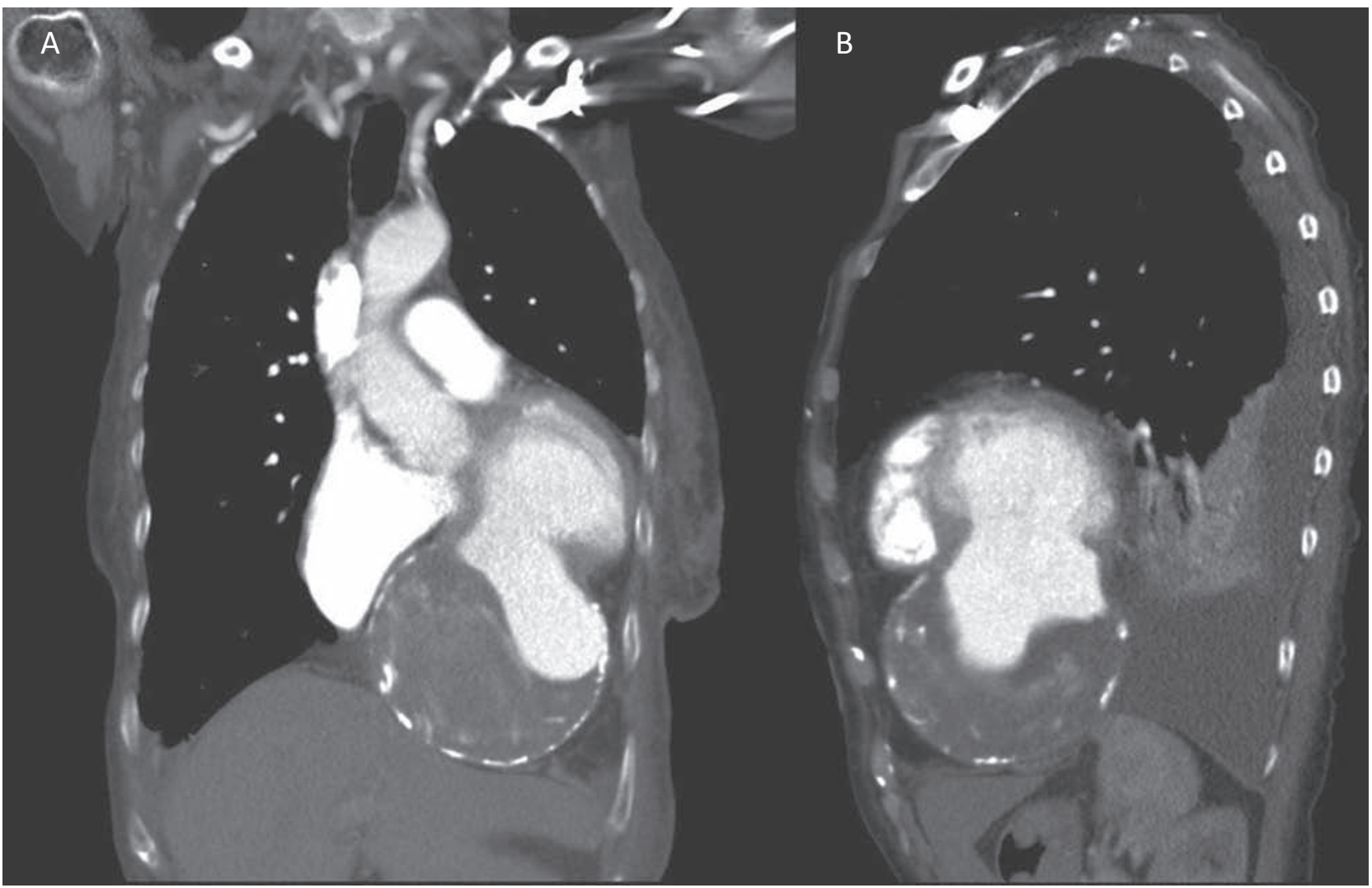

Fig 1. Computerised tomography (CT) chest image of patient with left ventricular aneurysm. $A$ - coronal contrast enhanced $C T$ chest image showing a large, wide necked, aneurysm projecting inferiorly from the left ventricle. There is mural thrombus and peripheral calcification. B - sagittal CT chest image again showing large left ventricular aneurysm.

An 86-year-old female presented to the emergency department with a history of worsening breathlessness for 3 days and decreased level of consciousness.

On examination, she was drowsy, in respiratory distress, tachycardic and hypotensive. On auscultation of the chest,

Authors: ${ }^{\text {A }}$ medical registrar, William Harvey Hospital, Ashford, UK; ${ }^{B}$ foundation doctor, William Harvey Hospital, Ashford, UK; ${ }^{C}$ Consultant radiologist, William Harvey Hospital, Ashford, UK; ${ }^{\text {D }}$ consultant respiratory physician, William Harvey Hospital, Ashford, UK crackles were heard in the lower zones bilaterally, and a pansystolic murmur was audible over the precordium, with radiation to the axilla. Arterial blood gas analysis showed severe type II respiratory failure.

She had suffered a myocardial infarction 20 years previously. She was treated with non-invasive ventilation, antibiotics and diuretics. Over the next 24 hours, there was marked improvement in her clinical condition.

To investigate the cause of her respiratory failure, a computerised tomography scan of the chest was obtained (Fig 1), which showed cardiomegaly and a large left ventricular (LV) aneurysm projecting inferiorly, with a large 
mural thrombus. It had compressed the right atrium and displaced the inferior vena cava. There was bilateral pleural effusion.

The definition of a true LV aneurysm is a discrete ballooning of scarred or fibrotic myocardial wall (often without muscle or containing necrotic muscle) arising from the left ventricle. The involved segment is either akinetic or dyskinetic with paradoxical movement during systole. LV aneurysms often occur as a result of a healed transmural myocardial infarction; however, less common causes include hypertrophic cardiomyopathy and Chagas disease.

A number of serious complications can occur as a consequence of LV aneurysm, particularly heart failure, ventricular arrhythmias and thromboembolism.

The identification of a mural thrombus in patients with post-infarction LV aneurysm indicates anticoagulation therapy should be considered; however, the risk of embolism appears to be low with a chronic aneurysm diagnosed at least 1 month after a myocardial infarction. These thrombi have presumably organised or been enthothelialised and appear to rarely embolise. Therefore, anticoagulation may not be warranted in such patients. ${ }^{1}$

Treatment is largely aimed at medical management of the complications of the aneurysm, while aneurysmectomy is considered in patients who have intractable ventricular arrhythmias and/or heart failure unresponsive to medical therapy. ${ }^{2}$

\section{Conflicts of interest}

The authors have no conflicts of interest to declare.

\section{Acknowledgements}

Written consent was obtained from the patient to publish the clinical details and images in this article.

\section{References}

1 Lapeyre AC 3rd, Steele PM, Kazmier FJ et al. Systemic embolism in chronic LV aneurysm: incidence and the role of anticoagulation. J Am Coll Cardiol 1985;6:534.

2 Antman EM, Anbe DT, Armstrong PW et al. ACC/AHA guidelines for the management of patients with ST-elevation myocardial infarction. Circulation 2004;110:588-636.

Address for correspondence: Dr E Denny, William Harvey Hospital, Kennington, Ashford TN24 0LZ, UK. Email: eleanor.denny@nhs.net 